Article

\title{
Novel Cd (II) Coordination Polymers Afforded with EDTA or Trans-1,2-Cdta Chelators and Imidazole, Adenine, or 9-(2-Hydroxyethyl) Adenine Coligands
}

\author{
Jeannette Carolina Belmont-Sánchez ${ }^{1}$, María Eugenia García-Rubiño ${ }^{2}$, Antonio Frontera ${ }^{3}{ }^{\mathbb{D}}$, \\ Antonio Matilla-Hernández ${ }^{1}\left(\mathbb{D}\right.$, Alfonso Castiñeiras ${ }^{4}\left(\mathbb{D}\right.$ and Juan Niclós-Gutiérrez ${ }^{1, *(\mathbb{D}}$ \\ 1 Department of Inorganic Chemistry, Faculty of Pharmacy, University of Granada, 18071 Granada, Spain; \\ carol.bs.quimic@hotmail.com (J.C.B.-S.); amatilla@ugr.es (A.M.-H.) \\ 2 Departamento Fisicoquímica, Facultad de Farmacia, Universidad de Granada, 18071 Granada, Spain; \\ rubino@ugr.es \\ 3 Departament de Química, Universitat de les Illes Balears, Crta. de Valldemossa km 7.5, \\ 07122 Palma de Mallorca (Baleares), Spain; toni.frontera@uib.es \\ 4 Department of Inorganic Chemistry, Faculty of Pharmacy, University of Santiago de Compostela, \\ 15782 Santiago de Compostela, Spain; alfonso.castineiras@usc.es \\ * Correspondence: jniclos@ugr.es
}

Received: 11 April 2020; Accepted: 7 May 2020; Published: 11 May 2020

\begin{abstract}
Three mixed-ligands of $\mathrm{Cd}(\mathrm{II})$ coordination polymers were unintentionally obtained: $\left\{\left[\mathrm{Cd}\left(\mu_{3}-\mathrm{EDTA}\right)(\mathrm{Him}) \cdot \mathrm{Cd}(\mathrm{Him})\left(\mathrm{H}_{2} \mathrm{O}\right)_{2}\right] \cdot \mathrm{H}_{2} \mathrm{O}\right\}_{\mathrm{n}}(\mathbf{1}),\left\{\left[\mathrm{Cd}\left(\mu_{4}-\mathrm{CDTA}\right)(\text { Hade }) \cdot \mathrm{Cd}(\text { Hade })_{2}\right]\right\}_{\mathrm{n}}$ (2), and $\left\{\left[\mathrm{Cd}\left(\mu_{3}-\mathrm{EDTA}\right)\left(\mathrm{H}_{2} \mathrm{O}\right) \cdot \mathrm{Cd}(\mathrm{H} 9 \text { heade })\left(\mathrm{H}_{2} \mathrm{O}\right)\right] \cdot 2 \mathrm{H}_{2} \mathrm{O}\right\}_{n}$ (3), having imidazole (Him), adenine (Hade) or 9-(2-hydroxyethyl)adenine (9heade) as the $\mathrm{N}$-heterocyclic coligands. Compounds $\mathbf{2}$ and $\mathbf{3}$ were obtained by working with an excess of corresponding N-heterocyclic coligands. The single-crystal X-ray diffraction structures and thermogravimetric analyses are reported. The chelate moieties in all three compounds exhibit hepta-coordinated Cd centers, whereas the non-chelated Cd center is five-coordinated in $\mathbf{1}$ and six-coordinated in $\mathbf{2}$ and $\mathbf{3}$. Him and Hade take part in the seven-coordinated chelate moieties in $\mathbf{1}$ and $\mathbf{2}$, respectively. In contrast, 9heade is unable to replace the aqua ligand of the chelate [Cd (EDTA) $\left(\mathrm{H}_{2} \mathrm{O}\right)$ ] moiety in 3 . The thermogravimetric analysis (TGA) behavior of [Cd $\left(\mathrm{H}_{2}\right.$ EDTA) $\left.\left(\mathrm{H}_{2} \mathrm{O}\right)\right] \cdot 2 \mathrm{H}_{2} \mathrm{O}$ in $\mathbf{1}$ and 3 leads to a residue of $\mathrm{CdO}$, whereas the $\mathrm{N}$-rich compound 2 yields $\mathrm{CdO} \cdot \mathrm{Cd}\left(\mathrm{NO}_{3}\right)_{2}$ as a residue. Density functional theory (DFT) calculations along with molecular electrostatic potential (MEP) and quantum theory of atoms-in-molecules computations were performed in adenine (compound 2) and (2-hydroxyethyl)adenine (compound 3) to analyze how the strength of the $\mathrm{H}$-bonding and $\pi$-stacking interactions, respectively, are affected by their coordination to the Cd-metal center.
\end{abstract}

Keywords: EDTA; CDTA; adenine; cadmium; polymers; crystal structure; DFT calculations

\section{Introduction}

Ethylenediaminotetracetic acid $\left(\mathrm{H}_{4} \mathrm{EDTA}\right)$ and its different anionic forms are the most investigated metal chelators among the amino-polycarboxylic/carboxylate ligands. Interest has been focused in both the chemical and technological fields because of the efficient chelating properties and the well-known ability of carboxylate groups to display broad metal binding modes. The ability of EDTA to form up to five-membered metal- $N, N$ and metal- $N, O$ chelate rings enables its recognized capability to act as a hexadentate chelator with many metal ions (M). Moreover, the conformational flexibility of the metal- $N, N^{\prime}$-ethylenediamine ring seems to enhance the diversity of coordination modes. 
We have paid attention to the bridging role in $\mathrm{M}(\mu$-EDTA)M entities, acting as two $N$-substituted iminodiacetate moieties linked together by the flexible ethylene spacer. A search in the Cambridge Structural Database (hereafter CSD) affords around forty different crystallographic results of these kinds of complexes with $\mathrm{M}=\mathrm{Cu}^{\mathrm{II}}$ (6 compounds), $\mathrm{Mo}^{\mathrm{V}}$ (27 compounds), $\mathrm{W}^{\mathrm{V}}$ (9 compounds), $\mathrm{Tc}^{\mathrm{V}}$ (1 compound), or $\operatorname{Re}(\mathrm{I})$ (1 compound) and also including an Mo-W bimetallic example. Interestingly $\mathrm{M}$-( $\mu$-EDTA)-M moieties with first-row transition metal ions refer only to six compounds of $\mathrm{Cu}$ (II). Such results include the polymer $\left\{\left[\mathrm{Cu}_{2}\left(\mu_{2}\right.\right.\right.$-EDTA $\left.\left.)\left(\mathrm{H}_{2} \mathrm{O}\right)_{2}\right] \cdot 2 \mathrm{H}_{2} \mathrm{O}\right\}$ [CUEDTA01 and CUEDTA10 in CSD], the molecular compound $\left[\mathrm{Cu}_{2}\left(\mu_{2}-\mathrm{EDTA}\right)(\mathrm{py})_{2}\right] \cdot 2 \mathrm{H}_{2} \mathrm{O}$ (py = pyridine, NAMJOB in CSD) [1], the polymer $\left[\mathrm{Cu}_{2}\left(\mu_{4} \text {-EDTA)(3OH-py) }\right)_{n}\right]_{\mathrm{n}}(3 \mathrm{OH}-\mathrm{py}=3$-hydroxypiridine, PEZRES in CSD), and two sophisticated polymers having the $\left[\mathrm{Cu}_{2}\left(\mu_{4}\right.\right.$-EDTA] moiety, silicate or phosphate, a poly-oxo-poly-wolframate anion, $\mathrm{Na}^{+}$ions, and water molecules [2].

For a long time, we have been interested in the investigation of molecular recognition modes between copper(II) chelates and amino-purine bases (such as adenine, 2-aminopurine, 2,6-diaminopurine, and hypoxanthine) [3-13]. Our work also includes deaza- and aza-purines and closely related $\mathrm{N}$-heterocycles, related to at least one $\mathrm{N}$ atom in each five- or six-membered rings of the purine skeleton [5]. The main aim of this work was to extend the knowledge of mixed-ligand dinuclear $\mathrm{Cu}$ (II) complexes of the type ( $N$-ligand)M( $\mu$-EDTA) $N(N$-ligand) (such as NAMJOB [1] or PEZRES in CSD) to Cd (II), $\mu$-EDTA, or $\mu$-CDTA (where CDTA = trans-1,2-diaminocyclohexane-tetraacetate(4-) ion) as bridging-dinucleating chelators and imidazole (Him), adenine (Hade), or 9-(2-hydroxyethyl)adenine (9heade) as $\mathrm{N}$-heterocyclic donor coligands. The following $\mathrm{N}$-donor ligands were selected: the small heterocyclic fragment of adenine (Him), adenine itself (Hade), or the closely related synthetic nucleoside 9heade [13]. To this purpose, a series of syntheses were carried out maintaining a Cd (II):EDTA:CDTA ratio of 2:1:2 but different amounts of Him, Hade, or 9heade, from which the three reported polymers were crystallized. Hence, we describe the syntheses, thermal stability, and crystal structures of these novel compounds. For thermogravimetric analysis (TGA) comparison, [Cd( $\left.\mathrm{H}_{2} \mathrm{EDTA}\right)\left(\mathrm{H}_{2} \mathrm{O}\right] \cdot 2 \mathrm{H}_{2} \mathrm{O}$ [14] (ACAQOK in CSD) was also prepared. In the solid state of the polymer with adenine, an interesting network of $\mathrm{H}$-bonds is formed. Moreover, in compound 3 , antiparallel displaced $\pi$-stacking interactions are established. Both interactions were studied by density functional theory (DFT) calculations, focusing on the influence of the metal coordination on the relative strength of the $\pi$-stacking and H-bonds, which were estimated using the quantum theory of atoms-in-molecules (QTAIM) theory.

\section{Materials and Methods}

\subsection{Reagents}

$\mathrm{H}_{4}$ EDTA acid (TCI), trans- $\mathrm{H}_{4}$ CDTA (Aldrich), Him (Merck), adenine (Aldrich), 9heade (TCI, 98\%), and $\mathrm{CdCO}_{3}$ (Alfa Aesar, 98\%) were used as received. The synthetic purine-nucleoside 9heade can also prepared as reported by T.Y. Shen et al. [15]. Its purity was tested by elemental CHN-analysis, FT-IR spectroscopy, and thermogravimetric analysis (TGA). Its recrystallization in various polar solvents gives crystals of 9heade consistent with the three reported crystalline forms [16]. Also, the purity of $\mathrm{CdCO}_{3}(98 \%)$ was tested by thermogravimetric analysis (TGA) by the experimental final residue (CdO) that results in agreement of the calculated value within $1 \%$ of assumed experimental error.

\subsection{Crystallography}

Colorless needle crystals of compounds 1-3 were mounted on a glass fiber and used for data collection. Crystal data were collected at 100(2) K, using a Bruker D8 VENTURE PHOTON III-14 diffractometer. Graphite monochromated $\operatorname{MoK}(\alpha)$ radiation $(\lambda=0.71073 \AA)$ was used throughout. The data were processed with APEX2 [17] and corrected for absorption using SADABS (transmissions factors: 1.000-0.962) [18]. The structure was solved by direct methods using the program SHELXS-2013 [19] and refined by full-matrix least-squares techniques against $\mathrm{F}^{2}$ using SHELXL-2013 [19]. Positional and anisotropic atomic displacement parameters were refined for 
all non-hydrogen atoms. Hydrogen atoms were located in difference maps and included as fixed contributions riding on attached atoms with isotropic thermal parameters 1.2/1.5 times those of their carrier atoms. Criteria of a satisfactory complete analysis were the ratios of rms shifts to standard deviations less than 0.001 and no significant features in the final difference maps. Atomic scattering factors were taken from the International Tables for Crystallography [20]. Molecular graphics were plotted with PLATON [21]. A summary of the crystal data, experimental details, and refinement results for compounds 1-3 are listed in Table S1; Table S2-S4 list the with cadmium (II) coordination bond lengths and angles and $\mathrm{H}$-bonding information of 1-3. Crystallographic data for 1-3 were deposited in the Cambridge Crystallographic Data Center with the CCDC numbers 1995138-1995140.

\subsection{Other Physical Measurements}

Analytical data $(\mathrm{CHN})$ were obtained in a Fisons-Carlo Erba EA 1108 elemental micro-analyzer. TGA was carried out (r.t. $\left.-950^{\circ} \mathrm{C}\right)$ under an air flow $(100 \mathrm{~mL} / \mathrm{min})$ by a Shimadzu Thermobalance TGA-DTG-50H instrument. To identify the evolved gases, during each TGA experiment, a series of 35 time-spaced FT-IR spectra were recorded with a coupled FT-IR Nicolet Magna 550 spectrometer.

\subsection{Synthesis}

In order to minimize the presence of undesired by-products, the strategies of the synthetic procedures described below used $\mathrm{CdCO}_{3}$ (as metal ion source) and EDTA or CDTA chelating agents in their corresponding acid forms. These reactions were carried out in a Kitasato flask including its stopper but with its side outset open to maintain an open thermodynamic system that permitted gas flow. These syntheses yielded $\mathrm{CO}_{2}$ (easily removed) as the main by-product and water (that was used as a solvent).

\subsection{1. $\left\{\left[\mathrm{Cd}\left(\mu_{3} \text {-EDTA }\right)(\mathrm{Him}) \cdot \mathrm{Cd}(\mathrm{Him})\left(\mathrm{H}_{2} \mathrm{O}\right)_{2}\right] \cdot \mathrm{H}_{2} \mathrm{O}\right\}_{\mathrm{n}}(\mathbf{1})$}

$\mathrm{CdCO}_{3}(1 \mathrm{mmol}, 0.17 \mathrm{~g})$ and $\mathrm{H}_{4}$ EDTA $(0.5 \mathrm{mmol}, 0.15 \mathrm{~g})$ were reacted in water $(100 \mathrm{~mL})$ in a Kitasato flask at $50-70{ }^{\circ} \mathrm{C}$, with permanent stirring until a clear solution was obtained. The heating was ceased and then Him $(1.1 \mathrm{mmol}, 75 \mathrm{mg})$ was added at r.t. A clear reaction mixture was immediately obtained and then filtered without vacuum by a funnel provided with a G3-fritted glass disk (to remove any insoluble material) on a crystallization flask. The slow evaporation of the solution was controlled with the aid of a plastic film and produced the stable colorless crystals of $\mathbf{1}$ (two-three weeks at r.t.), which were removed and then dried in air at r.t. over several days. Yield: $\sim 75 \%$. Elemental analysis (\%): Calc. for $\mathrm{C}_{16} \mathrm{H}_{26} \mathrm{Cd}_{2} \mathrm{~N}_{6} \mathrm{O}_{11}$ : C 27.33, H 3.73, N 11.95; Found: C 27.21, H 3.64, N 11.95.

\subsection{2. $\left\{\left[\mathrm{Cd}\left(\mu_{4}-\mathrm{CDTA}\right)(\text { Hade }) \cdot \mathrm{Cd}(\text { Hade })_{2}\right]\right\}_{n}(2)$}

$\mathrm{CdCO}_{3}(1 \mathrm{mmol}, 0.17 \mathrm{~g})$ and $\mathrm{H}_{4} \mathrm{CDTA}(0.5 \mathrm{mmol}, 0.18 \mathrm{~g})$ were reacted in water $(100 \mathrm{~mL})$ in a Kitasato flask at $50{ }^{\circ} \mathrm{C}$, with permanent stirring for one day. A somewhat translucent solution was obtained. The heating was ceased and then Hade $(2 \mathrm{mmol}, 0.27 \mathrm{~g})$ was added at r.t. in small portions. The reaction mixture was filtered without vacuum by a funnel provided with a G3-fritted glass disk (to remove some withe material) on a crystallization flask. The slow evaporation of the solution was controlled with the aid of a plastic film and produced the stable colorless crystals of $\mathbf{1}$ (four weeks at r.t.), which were collected and then dried in air at r.t. for one weak. Yield: $\sim 60 \%$. This procedure represents $100 \%$ Hade in excess. Similar results were recently obtained using $50 \%$ Hade $(1.5 \mathrm{mmol})$ in excess. Elemental analysis (\%): Calc. for $\mathrm{C}_{29} \mathrm{H}_{33} \mathrm{Cd}_{2} \mathrm{~N}_{17} \mathrm{O}_{8}$ : C 35.82, H 3.42, N 24.49. Found: C 35.76, H 3.39, N 24.44.

\subsection{3. $\left\{\left[\mathrm{Cd}\left(\mu_{3} \text {-EDTA }\right)\left(\mathrm{H}_{2} \mathrm{O}\right) \cdot \mathrm{Cd}(\mathrm{H} 9 \text { heade })\left(\mathrm{H}_{2} \mathrm{O}\right)\right] \cdot 4 \mathrm{H}_{2} \mathrm{O}\right\}_{\mathrm{n}}($ 3)}

$\mathrm{CdCO}_{3}(1 \mathrm{mmol}, 0.17 \mathrm{~g})$ and $\mathrm{H}_{4}$ EDTA $(0.5 \mathrm{mmol}, 0.15 \mathrm{~g})$ were reacted in water $(100 \mathrm{~mL})$ in a Kitasato flask at $50{ }^{\circ} \mathrm{C}$, with permanent stirring until a clear solution was obtained. The heating 
was ceased and then H9heade $(2 \mathrm{mmol}, 0.36 \mathrm{~g})$ was added in small portions at r.t. A clear reaction mixture was obtained, left to cool, and then filtered without vacuum on a crystallization flask. The slow evaporation of the solution was controlled with the aid of a plastic film and produced the stable colorless crystals of 3 (three weeks at r.t.), which were collected and then dried in air at r.t. over several days. This procedure represents $100 \%$ H9heade in excess. These results were recently confirmed by repeating this procedure. Yield: $\sim 65 \%$. Elemental analysis (\%): Calc. for $\mathrm{C}_{17} \mathrm{H}_{33} \mathrm{Cd}_{2} \mathrm{~N}_{7} \mathrm{O}_{15}$ : $\mathrm{C} 25.51$, H 4.16, N 12.25, Cd 28,09; Found: C 25.43, H 4.04, N 12.19.

\subsection{4. $\left\{\left[\mathrm{Cd}\left(\mathrm{H}_{2} \operatorname{EDTA}\left(\mathrm{H}_{2} \mathrm{O}\right)\right] \cdot 2 \mathrm{H}_{2} \mathrm{O}\right\}_{n}\right.$}

$\mathrm{CdCO}_{3}(1 \mathrm{mmol}, 0.17 \mathrm{~g})$ and $\mathrm{H}_{4}$ EDTA $(1 \mathrm{mmol}, 0.29 \mathrm{~g})$ were reacted in water $(100 \mathrm{~mL})$ in a Kitasato flask at $50-70{ }^{\circ} \mathrm{C}$, with permanent stirring until a clear solution was obtained, which was left to cool at r.t. and then was filtered without vacuum (to remove any insoluble material) on a crystallization flask. The slow evaporation of the solution (controlled with the aid of a plastic film) produced the well-shaped colorless crystals of the desired product (two-three weeks at r.t.), which were removed and then dried in air at r.t. over several days. Yield: $\sim 80 \%$. Elemental analysis (\%): Calc. for $\mathrm{C}_{10} \mathrm{H}_{20} \mathrm{CdN}_{2} \mathrm{O}_{11}$ : C 26.30, H 4.41, N 6.13; Found: C 26.21, H 4.34, N 6.09. Polynova et al. [14] synthesized this compound by reaction between $\mathrm{CdSO}_{4} \cdot \mathrm{xH}_{2} \mathrm{O}(\mathrm{x}=2.67)$ and $\mathrm{Na}_{2} \mathrm{H}_{2}$ EDTA in water.

\subsection{Theoretical Methods}

All DFT calculations were carried out using the Gaussian-16 program [22] at the PBE1PBE-D3/def2-TZVP level of theory and using the crystallographic coordinates. The formation energies of the assemblies were evaluated by calculating the difference between the total energy of the assembly and the sum of the monomers that constitute the assembly, which were kept frozen. The molecular electrostatic potential was computed at the same level of theory and plotted onto the 0.001 a.u. isosurface. The quantum theory of atoms-in-molecules (QTAIM) [23] analysis was carried out at the same level of theory by means of the AIMAll program [24].

\section{Results and Discussion}

The following sections highlight the relevant structural features of compounds $\mathbf{1}$ to $\mathbf{3}$ and their thermal stability. Detailed tables with coordination bond lengths and angles as well as data concerning the H-bonds are supplied as Supporting Information (See Tables S2-S4). Tables summarizing TGA results are given as Supporting information (Tables S5-S8).

\subsection{Synthetic Considerations}

The utilization of cadmium carbonate and the acid form of the chelators for the syntheses of metal complexes reported herein. The synthesis $\left[\mathrm{Cd}\left(\mathrm{H}_{2}\right.\right.$ EDTA) $\left.\left(\mathrm{H}_{2} \mathrm{O}\right)\right]$ (ACAQOK in CSD) is supported by the reaction:

$$
\mathrm{CdCO}_{3}+\mathrm{H}_{4} \text { EDTA } \rightarrow\left[\mathrm{Cd}\left(\mathrm{H}_{2} \text { EDTA }\right)\left(\mathrm{H}_{2} \mathrm{O}\right)\right]+\mathrm{CO}_{2} \uparrow
$$

where two protons from the $\mathrm{H}_{4}$ EDTA acid react with carbonate anion yielding $\mathrm{H}_{2} \mathrm{O}$ (the used solvent) and $\mathrm{CO}_{2}$ (as an easily removable by-product).

Analogously, we can write:

$$
2 \mathrm{CdCO}_{3}+\mathrm{H}_{4} \mathrm{EDTA} \rightarrow\left[\mathrm{Cd}_{2}(\mu-\mathrm{EDTA})\right]+2 \mathrm{CO}_{2} \uparrow+2 \mathrm{H}_{2} \mathrm{O}
$$

where

$$
2 \mathrm{CO}_{3}{ }^{2-}+4 \mathrm{H}^{+} \rightarrow 2 \mathrm{CO}_{2} \uparrow+2 \mathrm{H}_{2} \mathrm{O} .
$$

This is a convenient synthetic strategy because with this simple process $\mathrm{CO}_{2}$ and water are the unique by-products. The $\mathrm{CO}_{2}$ is easy removed by the aid of simple physical actions, such as heating and/or stirring and/or moderate vacuum (or an appropriate combination of them). The stoichiometric 
reaction that yields the formation of the polymer $\left\{\left[\mathrm{Cd}_{2}\left(\mu_{7}-\mathrm{EDTA}\right)\right] \cdot \mathrm{H}_{2} \mathrm{O}\right\}_{\mathrm{n}}$ (FAFJON in CSD) is given below:

$$
\text { 2n } \mathrm{CdCO}_{3}+\mathrm{n} \mathrm{H}_{4} \text { EDTA } \rightarrow\left\{\left[\mathrm{Cd}_{2}\left(\mu_{7} \text {-EDTA }\right)\right] \cdot \mathrm{H}_{2} \mathrm{O}\right\}_{\mathrm{n}}+2 \mathrm{n} \mathrm{CO}_{2} \uparrow+\mathrm{n} \mathrm{H}_{2} \mathrm{O}
$$

The appropriate utilization of $\mathrm{H}_{4}$ EDTA or $\mathrm{H}_{4}$ CDTA and N-heterocyclic coligands yields the polymeric compounds $\mathbf{1}$ to 3 . For example, in compound $\mathbf{1}$ the stoichiometric reaction can be written as:

$$
\begin{gathered}
2 \mathrm{n} \mathrm{CdCO}_{3}+\mathrm{n} \mathrm{H}_{4} \text { EDTA }+2.2 \mathrm{n} \mathrm{Him}+\mathrm{n} \mathrm{H}_{2} \mathrm{O} \text { (solvent) } \rightarrow \\
\rightarrow\left\{\left[\mathrm{Cd}\left(\mu_{3} \text {-EDTA }\right)(\mathrm{Him}) \cdot \mathrm{Cd}(\mathrm{Him})\left(\mathrm{H}_{2} \mathrm{O}\right)_{2}\right] \cdot \mathrm{H}_{2} \mathrm{O}\right\}_{\mathrm{n}}(\mathbf{1})+2 \mathrm{n} \mathrm{CO}_{2} \uparrow+0.2 \mathrm{n} \mathrm{Him} .
\end{gathered}
$$

In this case, the crystallization of $\mathbf{1}$ needs a very small number of water molecules (from the solvent) and, simultaneously, a small amount of Him (used in $10 \%$ of excess) remains in solution.

\subsection{Thermal Stability of [Cd( $\left.\left.\mathrm{H}_{2} \mathrm{EDTA}\right)\left(\mathrm{H}_{2} \mathrm{O}\right)\right] \cdot 2 \mathrm{H}_{2} \mathrm{O}$ and the Polymeric Compounds 1 to 3}

The following sections highlight the relevant structural features of compounds 1 to 3 and their thermal stability.

Under air-dry flow, the weight loss versus temperature in complex $\left[\mathrm{Cd}\left(\mathrm{H}_{2} \mathrm{EDTA}\right)\left(\mathrm{H}_{2} \mathrm{O}\right)\right] \cdot 2 \mathrm{H}_{2} \mathrm{O}$ consists of five steps (Figure 1a). The experimental results and assignations are summarized in Table S5.
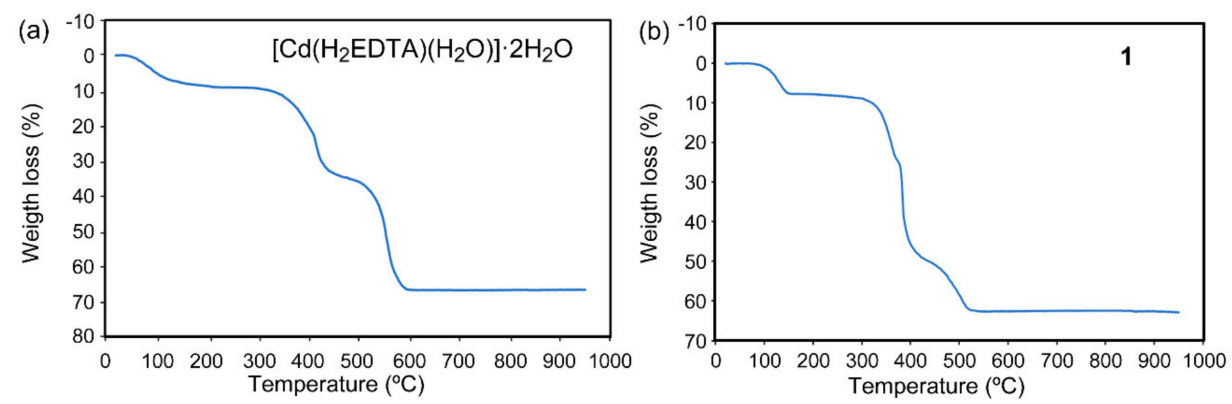

Figure 1. Weight loss versus temperature in the TGA of $\left[\mathrm{Cd}\left(\mathrm{H}_{2} \mathrm{EDTA}\right)\left(\mathrm{H}_{2} \mathrm{O}\right)\right] \cdot 2 \mathrm{H}_{2} \mathrm{O}($ sample: $9.99 \mathrm{mg}$; r.t. to $\left.950{ }^{\circ} \mathrm{C}\right)(\mathbf{a})$ and compound $\mathbf{1}\left(10.95 \mathrm{mg}\right.$; r.t. to $\left.950{ }^{\circ} \mathrm{C}\right)(\mathbf{b})$.

The first step $\left(25-185{ }^{\circ} \mathrm{C}\right)$ in the TGA of $\left[\mathrm{Cd}\left(\mathrm{H}_{2}\right.\right.$ EDTA $\left.)\left(\mathrm{H}_{2} \mathrm{O}\right)\right] \cdot 2 \mathrm{H}_{2} \mathrm{O}$ agrees with the loss of non-coordinated water, because most of this lost weight occurs below $100{ }^{\circ} \mathrm{C}$. The experimental data in the second step is higher than the calculated value, considering the loss of all aqua ligands as a consequence of the partial burning of the protonated organic ligand that could start before the end this step $\left(275^{\circ} \mathrm{C}\right)$. The formation of ammonia was not observed from the burning of $\mathrm{H}_{2} \mathrm{EDTA}^{2-}$. The third step yields $\mathrm{C}$-oxides and water. The last two steps produce methane, trace amounts of ethylene, and the three commonly observed $\mathrm{N}$-oxides $\left(\mathrm{N}_{2} \mathrm{O}, \mathrm{NO}\right.$, and $\left.\mathrm{NO}_{2}\right)$. The final residue seems to be non-pure $\mathrm{CdO}$.

The TGA plot for compound $\mathbf{1}$ is shown in Figure $1 \mathrm{~b}$ and the corresponding results are summarized in Table S6. Compound $\mathbf{1}$ essentially loses the uncoordinated water and both aqua ligands in the first step, from room temperature (r.t.) to $185{ }^{\circ} \mathrm{C}$. Organic ligands burn in the remaining steps, but mainly between 300 and $560{ }^{\circ} \mathrm{C}$ (steps 3-5). On the basis of the above for the molecular compound $\left[\mathrm{Cd}\left(\mathrm{H}_{2} \mathrm{EDTA}\right)\left(\mathrm{H}_{2} \mathrm{O}\right)\right] \cdot 2 \mathrm{H}_{2} \mathrm{O}$, the gases evolved in the third step suggest a partial overlap of these processes. Indeed, the weight loss in the last step (12.55\%) is lower than expected for the loss of $2 \mathrm{Him}$ ligands $(19.36 \%)$. The observed weight for the final residue at 560 and $950{ }^{\circ} \mathrm{C}$ is consistent with the calculated weight for $2 \mathrm{CdO}$.

The TGA plot for compound $\mathbf{2}$ is shown in Figure 2a and the corresponding results are summarized in the Table S7. The crystal structure of compound $\mathbf{2}$ (see below) revealed that there is no water in this compound and hence a relevant thermal stability should be expected for it. However, the first step from room temperature to $260^{\circ} \mathrm{C}$ essentially shows water loss. Most of the weight loss occurs below $150{ }^{\circ} \mathrm{C}$. We have assumed that the fresh sample used was not completely dry. On this basis, the 
observed behavior agrees to a formula $\left\{\left[\mathrm{Cd}\left(\mu_{4} \text {-CDTA }\right)(\text { Hade }) \cdot \mathrm{Cd}(\text { Hade })_{2}\right] \cdot 4 \mathrm{H}_{2} \mathrm{O}\right]_{n}$. The calculated value to remove such water content is $6.90 \%$, in good agreement to the experimental value $(7.00 \%)$. No other hypothesis seems reasonable, because in this step, only water is lost (with small amounts of $\left.\mathrm{CO}_{2}\right)$. Above $560{ }^{\circ} \mathrm{C}$ a stable residue of $\sim 33.4 \%$ is formed. The calculated value to $2 \mathrm{CdO}(24.59 \%)$ is too low, however, it is well known that the burning of this N-rich polymer can change it to a (not necessarily stoichiometric) cadmium oxy-nitrate [25]. Indeed, an estimation for $\mathrm{CdO} \cdot \mathrm{Cd}\left(\mathrm{NO}_{3}\right)_{2}$ as a final residue leads to a quite reasonable calculated value $(\sim 35 \%)$; therefore, we tentatively assigned the residue to cadmium oxy-nitrate.
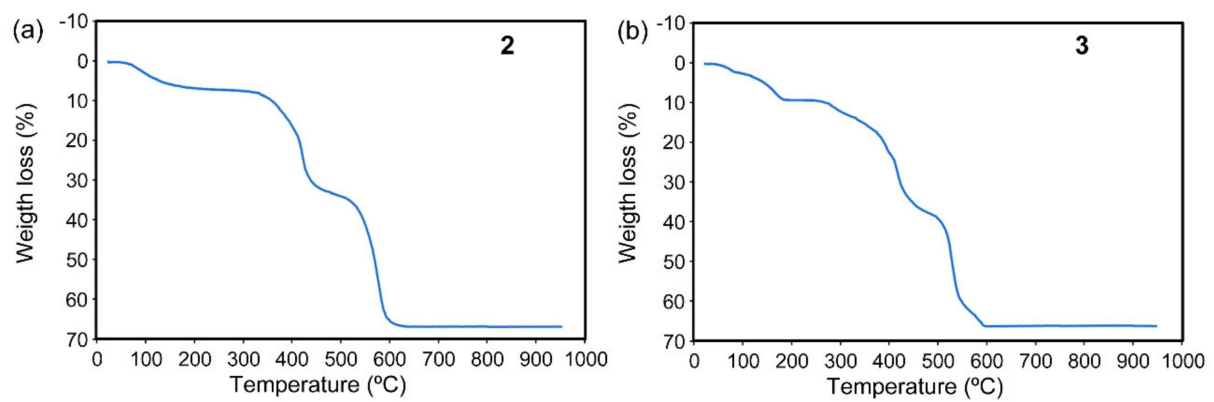

Figure 2. (a) Weight loss versus temperature (r.t. to $950{ }^{\circ} \mathrm{C}$ ) in the TGA of compound 2 (sample: $10.97 \mathrm{mg}$ ). (b) Weight loss versus temperature (r.t. to $950{ }^{\circ} \mathrm{C}$ ) in the TGA of compound 3 (sample: $11.04 \mathrm{mg}$ ).

The TGA plot for compound 3 is shown in Figure $2 b$ and the corresponding results are summarized in Table S8. Compound 3 shows a multi-step TGA behavior where the four first steps cannot be assigned (partial water-loss processes). However, all these steps and the corresponding range of temperatures match well to the amount of water and aqua ligands present in the compound. The remaining steps correspond to the burn of organic ligands. The final residue matches cadmium oxide.

\subsection{Structural Description}

\subsection{1. $\left\{\left[\mathrm{Cd}\left(\mu_{3} \text {-EDTA }\right)(\mathrm{Him}) \cdot \mathrm{Cd}(\mathrm{Him})\left(\mathrm{H}_{2} \mathrm{O}\right)_{2}\right] \cdot \mathrm{H}_{2} \mathrm{O}\right\}_{\mathrm{n}}(1)$}

This section highlights the relevant structural features of compounds $\mathbf{1}$ to 3 . The Supporting Information contains detailed data of coordination bond lengths and angles (Table S2) as well as H-bonds (Table S3) and $\pi$-stacking interactions (only found in $\mathbf{2}$ and 3, Table S3).

Compound 1 consists of 1D-polymeric chains running parallel to the $a$ axis of the crystal. The asymmetric unit shows two non-equivalent metallic centers, $\mathrm{Cd} 1$ and $\mathrm{Cd} 2$ (Figure 3 and Table S2).

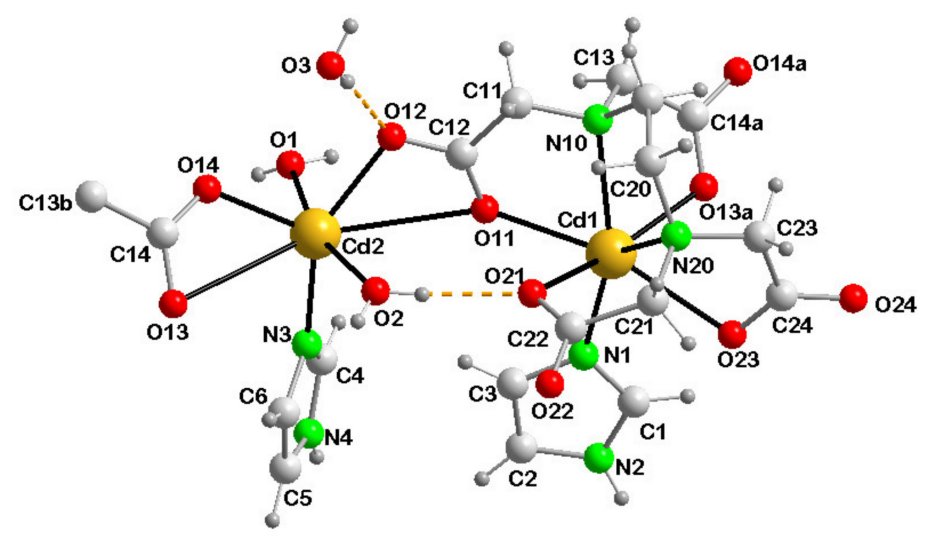

Figure 3. Perspective view of $\left\{\left[\mathrm{Cd}\left(\mu_{3} \text {-EDTA }\right)(\mathrm{Him}) \cdot \mathrm{Cd}(\mathrm{Him})\left(\mathrm{H}_{2} \mathrm{O}\right)_{2}\right] \cdot \mathrm{H}_{2} \mathrm{O}\right\}_{n}(\mathbf{1})$ showing the asymmetric unit, with the atom-numbering scheme and some $\mathrm{H}$ - bonds (orange dashed lines). 
The hepta-coordinated Cd1 atom is chelated by the $\mu_{3}$-EDTA ligand and is also linked to one Him ligand, defining a distorted mono-caped octahedral coordination. That is now recognized as a rather common coordination for this $[\mathrm{Kr}] 4 \mathrm{~d}^{10}$ soft Pearson's acid metal ion. Because all donor atoms of EDTA behave as hard Pearson's bases and imidazole is a borderline base with moderate steric relevance, the Cd1-N1(Him) bond (2.224(2) $\AA$ ) is the shortest one in this coordination polyhedron.

Another interesting feature is the unequal metal binding pattern featured by the two half-EDTA moieties in the polymeric chain of 1. Cd1-N20 (2.406(2) $\AA$, Cd1- O21 (2.389(2) ̊̊) and Cd1-O23 (2.556(2) $\AA$ ) bonds confer to the first half-EDTA the role of an N-substituted-iminodiacetate $\mathrm{N}, \mathrm{O}, \mathrm{O}^{\prime}$ - tridentate chelator, with Cd1-O21 and C1-N20 bonds ( 2.40 A) being shorter than the Cd1-O23 bond. Indeed, O23 seems to play the "mono-caped" role in the hepta-coordination of $\mathrm{Cd} 1$. Thus the-C22,O21,O22 and $-\mathrm{C} 23, \mathrm{O} 23, \mathrm{O} 24$ carboxylate groups act as monodentates. This role probably relaxes the steric constraints related to the EDTA chelator and the implication of the O24-carboxylate atom as a triply-acceptor for the H-bonds (sees Table S3).

In clear contrast, the second half-EDTA moiety assumes the $\mu_{3}$-EDTA bridging role in the polymeric chain by means of its two nearly anti,syn-carboxylate groups. The torsion angles involved are: Cd1-O13-C14-O14 $-178.9^{\circ}$ and O13-C14-O14-Cd2 -6.0 ${ }^{\circ}$, Cd1-O11-C12-O12 -159.4 ${ }^{\circ}$ and $\mathrm{O} 11-\mathrm{C} 12-\mathrm{O} 12-\mathrm{Cd} 217.5^{\circ}$. The $\mathrm{N} 10, \mathrm{O} 11$, and $\mathrm{O} 13$ atoms give slightly dissimilar bond distances,

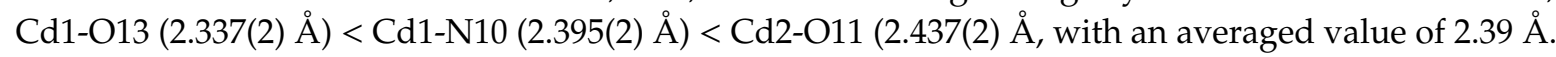
Hence, both carboxylate groups -C12,O11(anti),O12(syn) and -C14, O14(anti),O13(syn) are bidentate. That increases the denticity of the $\mu_{3}$-EDTA to eight.

The $\mathrm{Cd} 2$ center exhibits a roughly penta-coordination, with three rather short bond distances

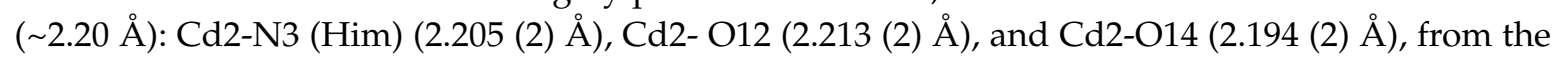
two anti,syn-carboxylate groups of adjacent Cd(EDTA) chelated moieties. Two aqua ligands fulfil this center, with Cd2-O1 and Cd2-O2 distances averaging 2.32 $\AA$. The angle O1-Cd2-O2 $\left(164.0(1)^{\circ}\right)$ is the closest to $180^{\circ}$ in the $\mathrm{Cd} 2$ coordination. A detailed inspection of this center locates $\mathrm{O} 11$ and $\mathrm{O} 13$ carboxylate donors of $\mathrm{Cd} 1$ at 3.011 and $3.163 \AA$ from Cd2 respectively. However, such weak contacts (also depicted in Figure 4) should not be considered as true coordination bonds for two main reasons. First, the $\mathrm{Cd} 2 \cdots \mathrm{O} 11$ and $\mathrm{Cd} 2 \cdots \mathrm{O} 13$ distances remarkably approach or even exceed the sum of the van der Waals radii $(1.52(\mathrm{O})+1.58(\mathrm{Cd})=3.10 \AA$ ). Second, such "contacts" seem clearly influenced by two

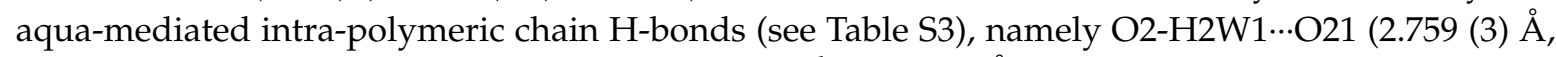

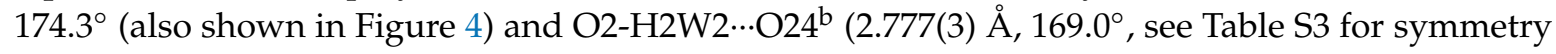
code). Such $\mathrm{H}$-bonds and other inter-chain aqua-mediated bonds (involving $\mathrm{O}_{1} \mathrm{H}_{2}$ ligand) build a $R_{4}^{3}(10)$ graph-set motif (Figure 5). The $\mathrm{H}_{2} \mathrm{O}^{\mathrm{d}}$ water molecule is also involved in one (Him) N4-H4 $\cdots \mathrm{O}^{\mathrm{d}}$ interaction (2.717 (3) $\AA, 175.7^{\circ}$, see Table S3 for symmetry code) as shown in Figure 4.

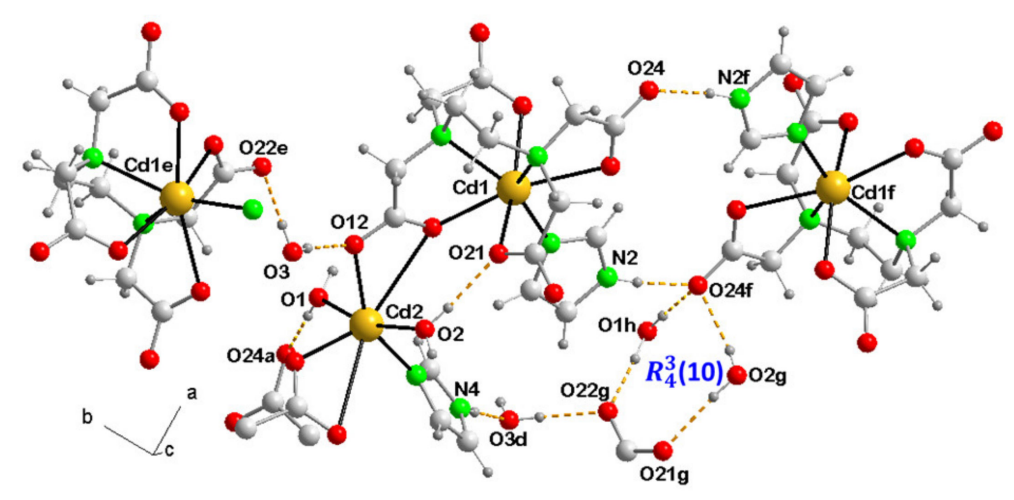

Figure 4. Plot of 1 showing some H-bonds (orange dashed lines) and the $R_{4}^{3}(10)$ graph-set motif involving both aqua ligands of the $\mathrm{Cd} 2$ center. For appropriate symmetry codes, see Table S3. 


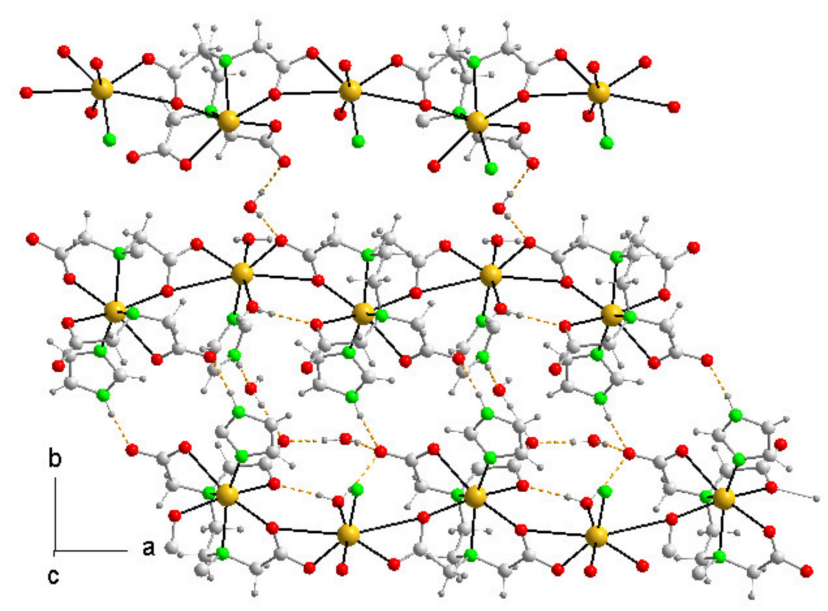

Figure 5. 2D H-bonded networks of $\mathbf{1}$ parallel to the ac plane are further pillared along the $\mathrm{b}$ axis

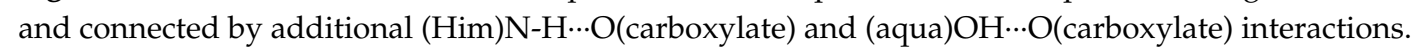
$\mathrm{H}$-bonds are depicted as orange dashed lines.

All N-H (imidazole) and O-H (aqua ligands or water) of $\mathbf{1}$ are involved in $\mathrm{N}-\mathrm{H} \cdots \mathrm{O}$ or $\mathrm{O}-\mathrm{H} \cdots \mathrm{O}$ interactions, with rather short (H-donor) $\cdots$ (acceptor) distances $\left(2.63-2.78 \AA\right.$ ) and open angles $\left(169-176^{\circ}\right)$. Polymeric chains are H-bonded in layers parallel to the $a c$ plane and in turn are H-bonded and pillared along the $b$ axis of the 3D-crystal (Figure 5). In this array, the O24-carboxylate atom acts as a triply $\mathrm{H}$-acceptor. The $\mathrm{H}_{2} \mathrm{O}$ (3) water molecule is involved in two $\mathrm{O} 3-\mathrm{H} \cdots \mathrm{O}$ (carboxylate) and one (Him) $\mathrm{N}-\mathrm{H} \cdots \mathrm{O}$ interactions.

\subsection{2. $\left[\mathrm{Cd}\left(\mu_{4}-\mathrm{CDTA}\right)(\text { Hade }) \cdot \mathrm{Cd}(\text { Hade })_{2}\right]_{\mathrm{n}}(2)$}

The crystal of compound $\left[\mathrm{Cd}\left(\mu_{4}-\mathrm{CDTA}\right)\left(\text { Hade) } \cdot \mathrm{Cd}(\text { Hade })_{2}\right]_{n}(2)\right.$ consists of fussed metallacycles (Figure 6) as graphite-like layers generating a 2D-polymer framework, parallel to the ab plane (Figure 7) and pillared along the $\mathrm{c}$ axis of the crystal. This configuration is because all carboxylate groups of the $\mu_{4}$-CDTA ligand display an anti,syn-bridging role.

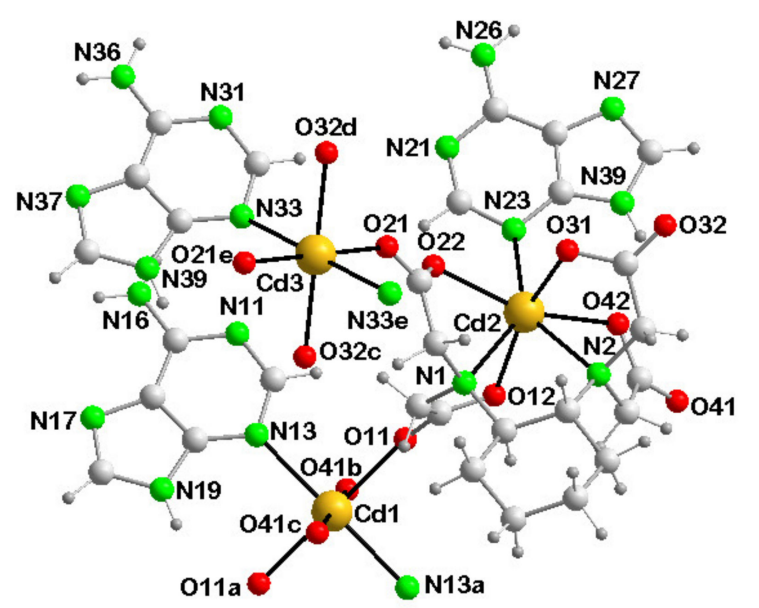

Figure 6. Asymmetric unit of $\left\{\left[\mathrm{Cd}\left(\mu_{4}-\mathrm{CDTA}\right)(\mathrm{Hade}) \cdot \mathrm{Cd}(\mathrm{Hade})_{2}\left(\mathrm{H}_{2} \mathrm{O}\right)_{2}\right] \cdot \mathrm{H}_{2} \mathrm{O}\right\}_{n}$ (2) showing the atom-numbering scheme. 


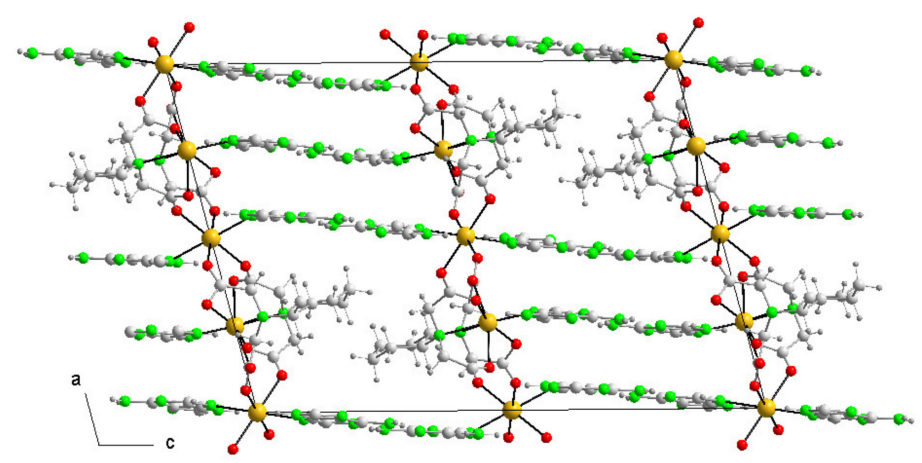

Figure 7. Crystal packing of 2 projected onto the ac plane. The polymeric layers parallel to the ab plane leave cyclohexane rings of CDTA chelators and Hade ligands oriented toward their external externa faces.

In the polymer, there are three crystallographically independent metallic centers. The Cd2 center of the fragment $\mathrm{Cd}\left(\mu_{4}\right.$-CDTA)(Hade) exhibits a distorted mono-caped octahedral coordination, where, interestingly, both $\mathrm{N}$-donors of the trans-1,2-CDTA ligand form the largest coordination bonds (Cd2-N1 2.457(5) and Cd2-N2 2.469(5) ̊̊). Two factors contribute to such polyhedron distortion: the fulfilled $4 \mathrm{~d}^{10}$ electronic configuration of the $\mathrm{Cd}(\mathrm{II})$ center and the remarkable steric constraints of the trans- $\mathrm{N}(\mathrm{e}), \mathrm{N}(\mathrm{e})-\mathrm{CDTA}$ conformer, which favors its hexadentate chelating role against the trans- $\mathrm{N}(\mathrm{a}), \mathrm{N}(\mathrm{a})-\mathrm{CDTA}$. The other four $\mathrm{Cd} 2-\mathrm{O}$ (carboxylate) bond distances of this polyhedron fall within the range 2.277(5)-2.364(5) $\AA$ (see Table S2). The hepta-coordination of Cd2 is accomplished by the Cd2-N3(Hade) bond, namely Cd2-N (23) 2.332(5) $\AA$. It is assumed that the N3 atom is the $\mathrm{N}$-heterocyclic atom with the lowest proton affinity [5]. However, the formation of this coordination bond is favored by the use of the most stable tautomer of the adenine, the (H(N9)ade), which in turn enables its cooperation with the intramolecular interligand interaction N29-29A ‥O42(CDTA) (2.713(8) $\AA, 137.2^{\circ}$ ). Moreover, this interaction permits the exocyclic amino group $-\mathrm{N}(26) \mathrm{H}_{2}$ (as $\mathrm{H}$-donor) and the $\mathrm{N} 1$ and N7 heterocyclic atoms (as H-acceptors) to participate in $\mathrm{N}-\mathrm{H} \cdots \mathrm{N}$ interactions, which contribute to the crystal parking (see below).

Each half-Cd2 $\left(\mu_{4}\right.$-CDTA)(Hade) unit connects with two non-equivalent but rather similar fragments, Cd1(Hade) $)_{2}$ and $\mathrm{Cd} 3(\text { Hade })_{2}$. Four O-carboxylate donors from Cd2 $\left(\mu_{4}\right.$-CDTA)(Hade) units build a centro-symmetric octahedral coordination to the $\mathrm{Cd} 1$ or $\mathrm{Cd} 3$ centers. Again, their trans-H(N9)ade ligands bind the corresponding metal centers by means of a cooperation of the

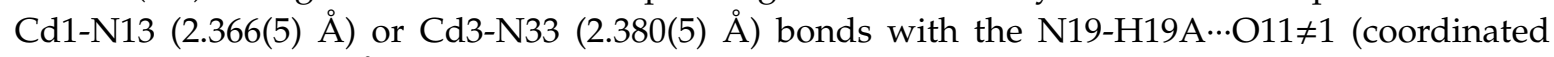
carboxylate, $2.969(7) \AA, 132.0^{\circ}$ ) or N39-H39A $\cdots \mathrm{O} 31 \neq 3$ (non-coordinated carboxylate) interligand interactions $(\neq 1=-x+2,-y,-z ; \neq 3=x, y+1, z)$. It is just the O11-coordinated or O31-non-coordinated nature of these $\mathrm{H}$-acceptor atoms that introduce the above-mentioned dissimilarity between the $\mathrm{Cd} 1$ or $\mathrm{Cd} 3$ centers. The 2D-polymeric layers leave the cyclohexane moieties of CDTA and the adenine ligands oriented toward their external faces (Figures 7 and 8).

The layers of this polymer pillared along the $\mathrm{c}$ axis are held together by pairs of rather linear

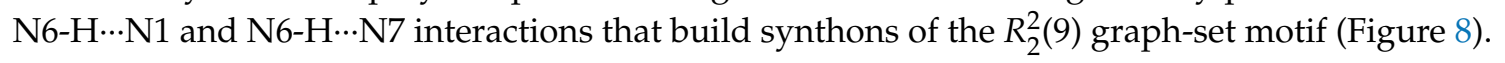




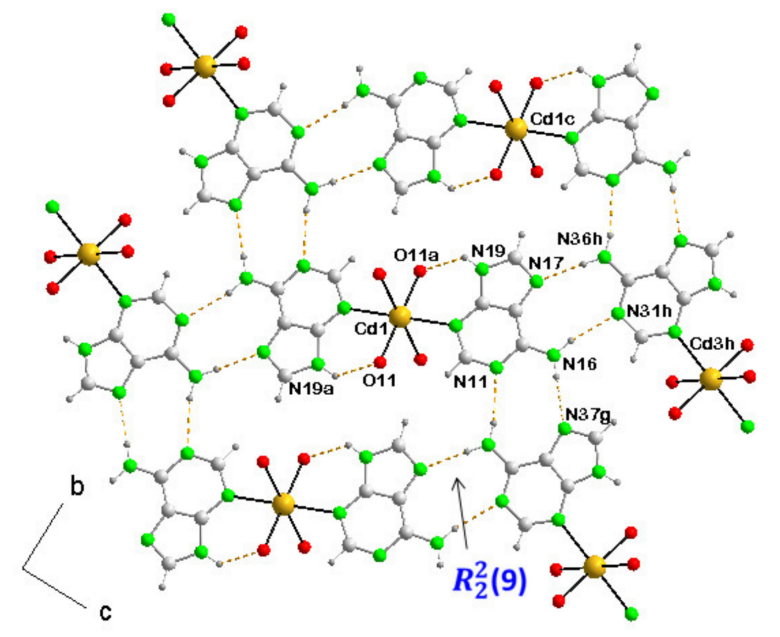

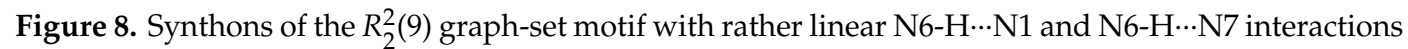
connect the external faces of the polymeric layers of compound 2. This plot also shows (for Cd1 center) the cooperation between the Cd-N3(Hade) bond and the $\mathrm{N} 9-\mathrm{H} \cdots \mathrm{O}$ (coordinated carboxylate) interligand interaction. Data of these H-bonds (orange dashed lines) are reported in Table S3.

\subsection{3. $\left\{\left[\mathrm{Cd}\left(\mu_{3} \text {-EDTA }\right)\left(\mathrm{H}_{2} \mathrm{O}\right) \cdot \mathrm{Cd}(\mathrm{H} 9 \text { heade })\left(\mathrm{H}_{2} \mathrm{O}\right)\right] \cdot 4 \mathrm{H}_{2} \mathrm{O}\right\}_{\mathrm{n}}$ (3)}

The asymmetric unit of this compound (see Figure 9) revealed its polymeric nature with two nonequivalent metallic centers. The first one corresponds to the $\mathrm{Cd} 1\left(\mu_{4}-\mathrm{EDTA}\right)\left(\mathrm{H}_{2} \mathrm{O}\right)$ cheated moiety, where the distorted hepta-coordination is fulfilled by the hexadentate chelating role of EDTA and the O2-aqua ligand. This unit implies that the synthetic 9heade ligand is unable to remove the $\mathrm{O} 2$-aqua ligand from the $\mathrm{Cd} 1$ center, in spite of the use a molar ratio of 2:1:2 of reagents $\mathrm{CdCO}_{3}: \mathrm{H}_{4}$ EDTA:9heade in the synthesis (which finally represents an excess of $100 \%$ of the N-heterocyclic coligand). The Cd1-O2(aqua) is the shortest bond (2.232(4) $\AA$ ) in this coordination polyhedron, where all other $\mathrm{Cd} 1-\mathrm{N}$ or $\mathrm{Cd} 1-\mathrm{O}$ bonds are in the rather narrow range of 2.34-2.46 (see Table S2). The differences in these last bond distances seem difficult to rationalize due to the sophisticated $\mu_{4}$-EDTA bridging role. Again, the two half moieties of EDTA display clearly distinct bridging functions. A half-(N32)-EDTA uses the monodentate-C38,O39, O40 group (Cd1-O39 2.332(3) $\AA$ ) along with the $\mu_{2}-\eta^{1}, \eta^{1}$ - anti,anti-C33,O35,O36 bridging group (C1-N32 2.383(3), Cd1-O35 2.344(3), and $\left.\mathrm{Cd} 2-\mathrm{O} 36^{\mathrm{b}} 2.268(3) \AA, \mathrm{b}=-\mathrm{x}+3 / 2, \mathrm{y}+1 / 2,-\mathrm{z}+3 / 2\right)$. The other half-(N21)-EDTA features the bidentate $\mu_{2}-\eta^{1}, \eta^{1}$ - anti,syn-C23,O24,O25 bridging group CdN21(Cd1-N21 2.425(3), Cd1-O24 2.341(3), and C2-O25 2.229(3) along with the tridentate $\mu_{2}-\eta^{2}, \eta^{1}-\mathrm{C} 27 \mathrm{O} 28, \mathrm{O} 29$ bridging group (Cd1-O28 2.418(3), $\mathrm{Cd} 2-\mathrm{O} 28^{\mathrm{a}} 2.411(3)$, and $\left.\mathrm{Cd} 2-\mathrm{O} 29^{\mathrm{a}} 2.445(3) \AA, \mathrm{a}=-\mathrm{x}+1 / 2, \mathrm{y}+1 / 2,-\mathrm{z}+3 / 2\right)$. In addition to the above mentioned $\mathrm{Cd} 2-\mathrm{O} 25, \mathrm{C} 2-\mathrm{O} 28$ and $\mathrm{C} 2-\mathrm{O} 29$ bonds, the $\mathrm{Cd} 2$ center fulfills its hexa-coordination with the Cd2-O1(aqua, 2.305(3) $\AA$ ) bond and the Cd2-N27(9hedae, 2.267(4) $\AA$ ) bonds. Two aspects are worth commenting on in this regard: (i) the $\mathrm{Cd} 2-\mathrm{O} 1$ (aqua) bond is not the shortest one around the $\mathrm{Cd} 2$ center and (ii) the N9-(2-hydroxiethyl) arm of 9heade favors the formation of the Cd2-N7 bond against Cd-N3 (as found with Hade in compound 2), because this coordination mode also implies the cooperation

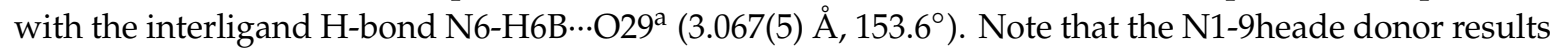
are disfavored for metal binding (against to N7-9heade) because of the great steric factor displayed by the adjacent exocyclic-(N6) amino group. 


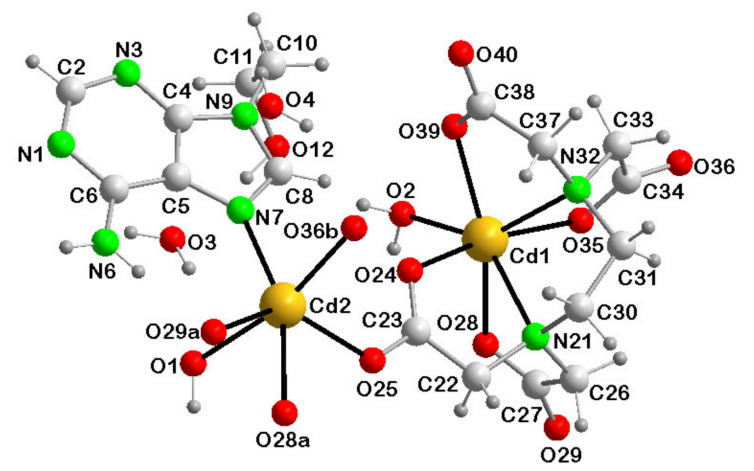

Figure 9. Perspective view of $\left\{\left[\mathrm{Cd}\left(\mu_{4} \text {-EDTA }\right)\left(\mathrm{H}_{2} \mathrm{O}\right) \cdot \mathrm{Cd}(9 \text { heade })\left(\mathrm{H}_{2} \mathrm{O}\right)\right] \cdot 4 \mathrm{H}_{2} \mathrm{O}\right\}_{\mathrm{n}}$ (3), showing the asymmetrical unit with the atom-numbering scheme.

The crystal of (3) consists of fused metallacycles (each having three Cd1 and three Cd2 centers, Figure 10) generating graphite-like 2D-polymeric frameworks, parallel to the ab plane (Figure 10b). These layers orientate 9 heade towards both external faces. Such layers are pillared along the $c$ axis, connected by many H-bonds (Figure 10 and Table S3) and a $\pi$-stacking interaction between the six-membered rings from the 9heade moieties (Figure 11 and Table S4)
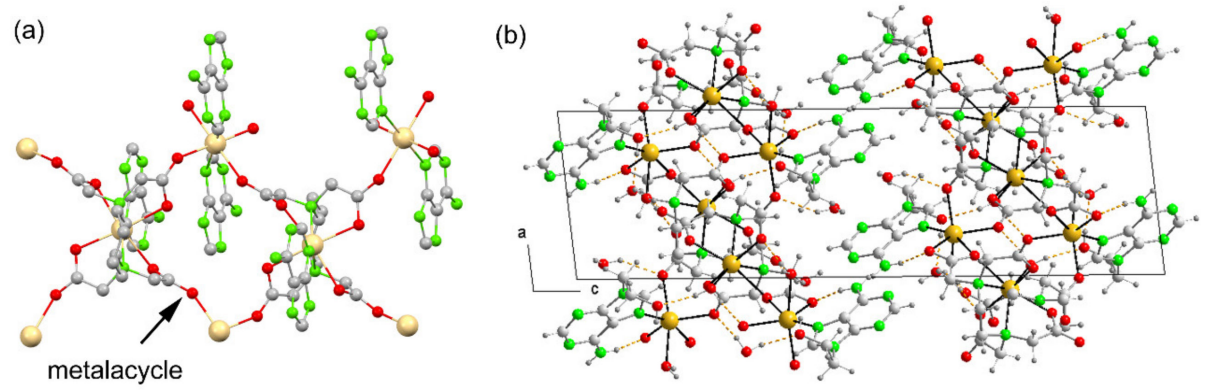

Figure 10. (a) A simplified plot of the hexanuclear metallacycle involved in the 2D-framework of (3) (b) Crystal packing of (3) projected onto the ac plane, also showing $\mathrm{H}$-bonding interactions (orange dashed lines), including the interligand interaction N6-H6B $\cdots O 29^{a}(a=-x+1 / 2, y+1 / 2,-z+3 / 2)$ that cooperates with the Cd-N7(9heade) bond.

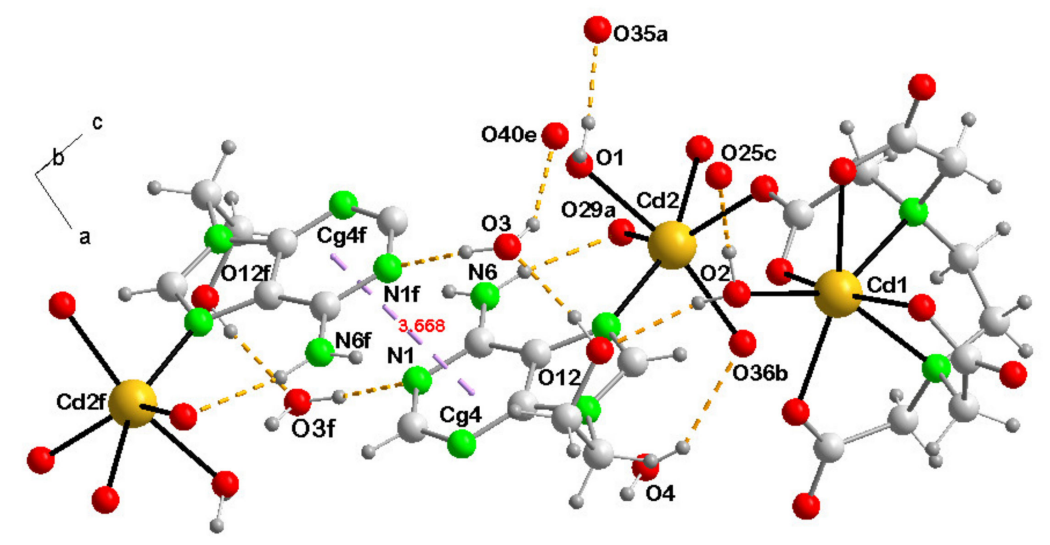

Figure 11. Diagram showing the hydrogen bond (orange dashed lines) and the inter-centroid distance of $\pi$-stacking interactions along the a-axis of (3).

\subsubsection{CSD Search}

Finally, we searched the Cambridge Structural Database (CSD) to investigate the structural features of $\mathrm{Cd}$ (II) complexes with chelators. Remarkably, only three Cd-CDTA derivatives were found in 
the database (Table S9). For instance, in the polymer $\left\{\left[\mathrm{Cd}\left(\mu_{4} \text {-CDTA) } \cdot \mathrm{Mn}\left(\mathrm{H}_{2} \mathrm{O}\right)_{4}\right] \cdot 3 \mathrm{H}_{2} \mathrm{O}\right\}_{n}\right.$, refcode GAZPOM, the metal ion is also hepta-coordinated by the hexadentate CDTA plus an O-carboxylate from a neighboring CDTA ligand. Table S9 summarizes structural details featured by the thirteen structures with Cd(II) chelates. Remarkably, most of these compounds are polymers, in agreement with the structures of compounds $1-3$. In addition, regardless of the chelating anion $\left(\mathrm{H}_{2} \mathrm{EDTA}^{2-}\right.$, HEDTA $^{3-}$ or EDTA ${ }^{4-}$ ), eleven of these compounds also exhibit hepta-coordinated Cd (II), with the hexa-denticity of the chelator implemented with an $\mathrm{O}$-(aqua or carboxylate) donor. The two exceptions for that (LOFKAT and IFELIP) correspond to structures where the HEDTA ${ }^{3-}$ chelator plays a pentaor tetra-dentate role in hexa-coordinated-Cd compounds, also having one S-donor (LOFKAT) or two $\mathrm{N}$-(heterocyclic) donor coligands (IFELIP).

\subsection{DFT Calculations}

The DFT study was focused on analyzing the interesting assemblies described above for compounds 2 and 3, in particular the influence of the coordination to $\mathrm{Cd}$ on the H-bonding and $\pi-\pi$ interaction strength. First of all, the molecular electrostatic potential (MEP) of the surfaces of adenine and adenine coordinated to $\mathrm{Cd}$ were computed (see Figure 12) in order to analyze how the MEP values at the $\mathrm{H}$-bond acceptor and donor groups of adenine change upon complexation. It can be observed that the $\mathrm{N} 3$ atom of adenine is the most nucleophilic/basic in agreement with the X-ray structure of compound 2 where the nucleobase is coordinated via an N3-atom. The MEP value at N1 is more negative than in N7. The most positive NH group corresponds to N9-H (+50 kcal/mol). Both $\mathrm{H}$-atoms of the exocyclic $\mathrm{NH} 2$ group exhibit identical MEP values $(+38 \mathrm{kcal} / \mathrm{mol})$. We used a monomeric model of compound 2 (see Figure 12b) where two carboxylate groups were protonated to keep the neutrality of the system. The effect of the coordination to the Cd (CDTA) system is an increase of the nucleophilicity at N1 and $\mathrm{N} 7$ and a slight reduction of the MEP values at the exocyclic $\mathrm{NH}_{2}$ group. This is due to the effect of the formation of two strong and intramolecular $\mathrm{H}$-bonds between the carboxylate ligands and the $\mathrm{N} 9-\mathrm{H}$ and $\mathrm{C} 2-\mathrm{H}$ groups with concomitant charge transference from the anion to the adenine ring. Therefore, the coordination of adenine to a Cd (CDTA) moiety increases the H-bond acceptor ability of adenine.

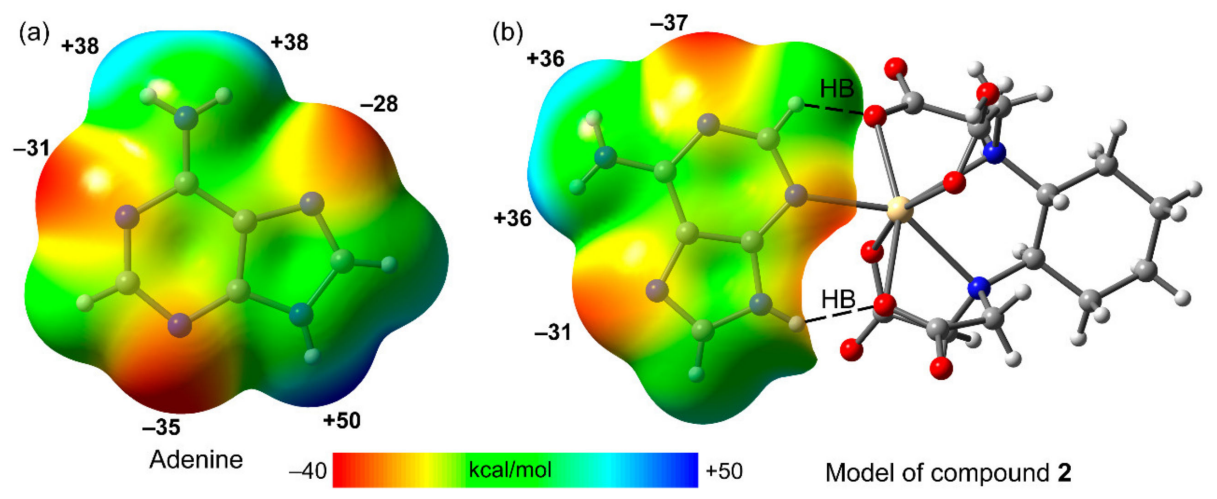

Figure 12. Molecular electrostatic potential (MEP) surfaces for adenine (a) and a model of compound 2 (b), highlighting the electropositive (blue) and electronegative (red) regions of each molecule. The values at selected points of the surface are given in $\mathrm{kcal} / \mathrm{mol}$. For the model of compound $\mathbf{2}$, the surface around the CDTA ligand has been omitted for clarity.

We selected the H-bonding network commented on in Figure 8 to analyze the energetic features of the H-bonds in 2. Figure 13a shows the H-bonded dimer of adenine $\left[R_{2}^{2}(9)\right.$ synthon] observed in the solid state of 2 . It presents a moderately strong dimerization energy $\left(\Delta \mathrm{E}_{1}=-9.5 \mathrm{kcal} / \mathrm{mol}\right)$ due to the formation of two $\mathrm{N}-\mathrm{H} \cdots \mathrm{N} \mathrm{H}$-bonds. Interestingly, the dimerization energy is the same as the dimer when the adenine is more favorable $\left(\Delta \mathrm{E}_{2}=-11.1 \mathrm{kcal} / \mathrm{mol}\right.$, see Figure 13b), in agreement with the MEP analysis, evidencing that the coordination to $\mathrm{Cd}$ reinforces the $\mathrm{H}-$ bonds. For compound 3 , 
we performed a similar analysis for the peculiar $\pi$-stacking motif observed in 3 , where the two $\mathrm{H}$-atoms of the 2-hydroxyethyl arms are pointing to the aromatic rings (see Figure 13c,d), so a combination of $\mathrm{C}-\mathrm{H} \cdots \pi$ and $\pi-\pi$ interactions are formed. For the study, a simplified model of 3 was used due to its polymeric nature. The carboxylate groups of EDTA were replaced by formate ligands in order to generate monomeric species (see small arrows in Figure 13d). The dimerization energy of the (2-hydroxyethyl)adenine is modest $\left(\Delta \mathrm{E}_{3}=-6.8 \mathrm{kcal} / \mathrm{mol}\right.$, see Figure 13c), however, it becomes more favorable, $\Delta \mathrm{E}_{4}=-8.0 \mathrm{kcal} / \mathrm{mol}$, upon coordination to $\mathrm{Cd}$, thus indicating that the antiparallel $\pi$-stacking is reinforced, likely due to an increase of the dipole $\cdots$ dipole interaction, since the dipole of the (2-hydroxyethyl)adenine molecule significantly increases upon coordination of $\mathrm{Cd}$.

.

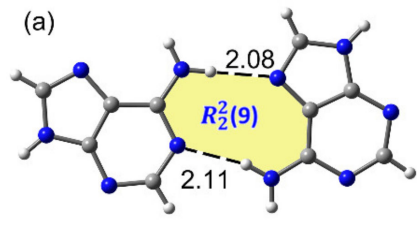

$\Delta \mathrm{E}_{1}=-9.5 \mathrm{kcal} / \mathrm{mol}$

(c)

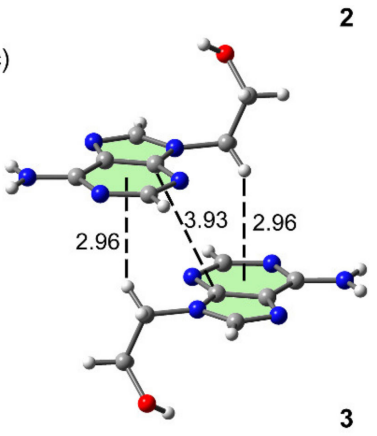

$\Delta \mathrm{E}_{3}=-6.8 \mathrm{kcal} / \mathrm{mol}$ (b)

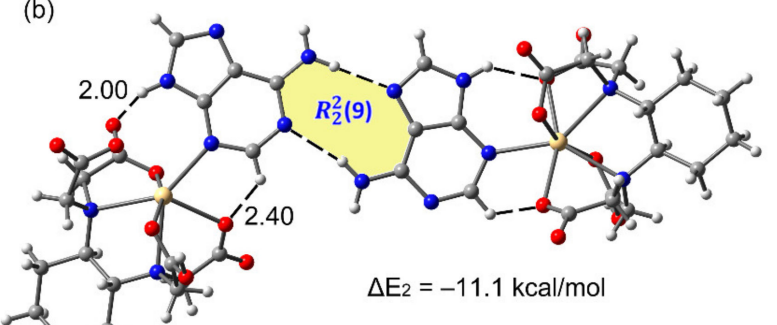

(d)

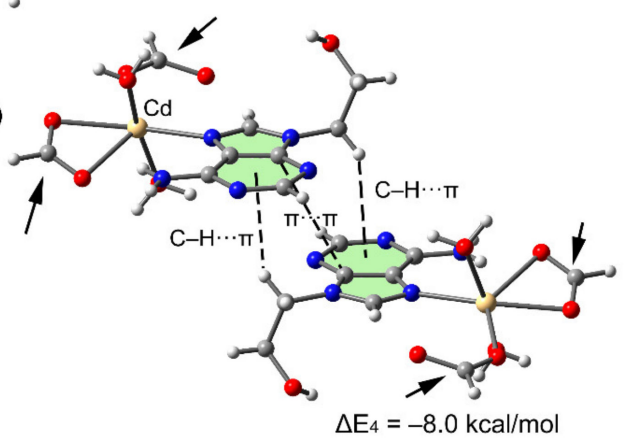

Figure 13. (a) Dimer of adenine retrieved from the X-ray solid state of $\mathbf{2}$, distances in $\AA$. (b) Dimer of a model of compound 2, distances in $\AA$. (c) Isolated $\pi, \pi$-stacked dimer of two 9heade molecules based on the X-ray structure of 3 . The distances are given in $\AA$. (d) $\pi, \pi$-stacked dimer of a theoretical model of compound 3.

Finally, we used the QTAIM method to further analyze the noncovalent interactions highlighted in Figure 13 for compounds 2 and 3 . A bond path and bond critical point (CP) interconnecting two atoms can be used as an unambiguous indication of interaction [26]. Moreover, this type of analysis has been recently used in similar systems [27-31]. The distribution of bond CPs and bond paths of the two motifs analyzed above are shown in Figure 14. The QTAIM analysis of the H-bonded dimer of 2 confirms the existence of the intramolecular $\mathrm{H}$-bonds between the carboxylate groups and the $\mathrm{C} 2-\mathrm{H}$ and N9-H bonds. Moreover, each intermolecular N-H $\cdots \mathrm{N}$ bond is characterized by a bond $\mathrm{CP}$ and bond path interconnecting the $\mathrm{H}$ and $\mathrm{N}$-bonds. Moreover, the $\mathrm{H}$-bonded dimer is further characterized by a ring $\mathrm{CP}$ as a consequence of the formation of the supramolecular $R_{2}^{2}(9)$ ring. The $\pi$-stacked dimer is characterized by four bond CPs, two of them interconnecting the $\mathrm{N}$-atoms of the adenine rings (see Figure 14b), thus confirming the antiparallel displaced $\pi$-stacking interaction. The other two CPs characterize the two symmetrically equivalent $\mathrm{C}-\mathrm{H} \cdots \pi$ interactions involving the $\mathrm{C}-\mathrm{H}$ bonds of the $\mathrm{sp}^{3} \mathrm{C}$-atoms of the side arms and the six-membered ring. The bond path connects the H-atom to one $\mathrm{C}$-atom of the ring. This combination of interactions agrees with the high dimerization energy obtained for this dimer of compound 3. 


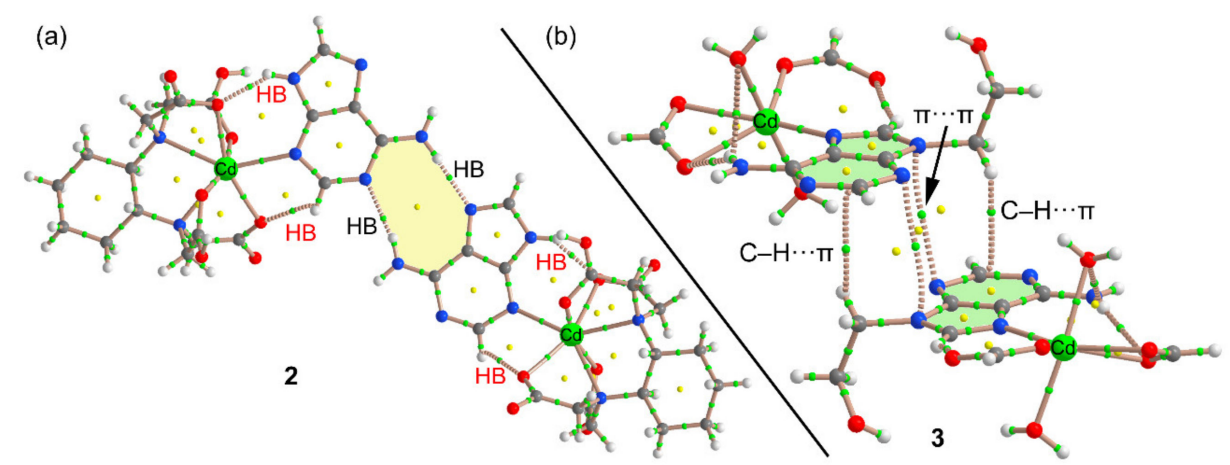

Figure 14. Distribution of bond and ring critical points (green and yellow spheres, respectively) and bond paths in two dimers of complexes 2 (a) and 3 (b).

\section{Concluding Remarks}

The main objective of the present work was the synthesis of molecular compounds of the general formula ( $N$-ligand)Cd( $\mu$-chelator)Cd( $N$-ligand) with EDTA $(\mathbf{1}, \mathbf{3})$ or trans-1,2-CDTA (2) chelating agents and closely related $N$-heterocyclic coligands, however, this aim was not accomplished. Instead of that, three novel coordination polymers were obtained and are reported on herein. In such compounds, the chelated Cd(II) metal centers are hepta-coordinated. It should be emphasized that only three Cd-CDTA derivatives were found in CSD database and in only one of them (GAZPOM) is the metal center also hepta-coordinated (hexadentate CDTA plus an O-carboxylate from an adjacent CDTA).

This work demonstrated that the cadmium(II) hepta-coordination of the Cd(EDTA or CDTA) chelate moieties in these kinds of polymers can be preserved with relatively small $N$-heterocyclic coligands (imidazole or adenine) but cannot use larger ones such as 9hedae. Our findings also open a promising window for further investigations on this matter with additional experiments.

Finally, the MEP analysis and DFT calculations show that the H-bonding and $\pi$-stacking interactions involving adenine or 9heade rings are enhanced upon coordination to $\mathrm{Cd}$.

Supplementary Materials: The following are available online at http://www.mdpi.com/2073-4352/10/5/391/s1.

Author Contributions: Conceptualization, J.N.-G., A.C., A.F., and A.M.-H.; methodology, all authors; software, A.M.-H., A.F., and A.C.; investigation, J.C.B.-S. and M.E.G.-R.; writing-original draft preparation, A.M.-H., M.E.G.-R., A.C., A.F., and J.N.-G., writing-review and editing, all authors, visualization, A.M.-H., M.E.G.-R., A.C., A.F., and J.N.-G., project administration, A.C., A.F., and J.N.-G.; funding acquisition, A.M.-H., A.F., and J.N.-G. All authors have read and agreed to the published version of the manuscript.

Funding: This research was funded by the Excellence Network “Metal Ions in Biological Systems" MetalBio CTQ2017-90802-REDT, the Research group FQM-283 (Junta de Andalucía), and MICIU/AEI of Spain (project CTQ2017-85821-R FEDER funds).

Acknowledgments: We thank the "Centre de Tecnologies de la Informació" (CTI), Universitat de les Illes Balears for computational facilities. We also thank all Projects for financial support.

Conflicts of Interest: The authors declare no conflict of interest.

\section{References}

1. Antsyshkina, A.S.; Sadikov, G.G.; Poznyak, A.L.; Sergienko, V.S. Crystal Structure of $\left[\mathrm{Cu}(\mathrm{Edta})(\mathrm{Py})_{2}\left(\mathrm{H}_{2} \mathrm{O}\right)_{2}\right] \cdot 2 \mathrm{H}_{2} \mathrm{O}$ and $\left[\mathrm{Cu}(\mathrm{Im})_{6}\right]\left\{\left[\mathrm{Cu}(\mathrm{Im})_{4}\right][\mathrm{Cu}(\mathrm{Edta})(\mathrm{Im})]_{2}\right\} \cdot 6 \mathrm{H}_{2} \mathrm{O}$, Products of the Interaction of (Ethylenediaminotetraacetato)diaquadicopper(II) with Pyridine and Imidazole. Russ. J. Inorg. Chem. 2006, 51, 241-252. [CrossRef]

2. Liu, H.; Xu, L.; Gao, G.-G.; Li, F.-Y.; Yang, Y.-Y.; Li, Z.-K.; Sun, Y. Two-dimensional layer architecture assembled by Keggin polyoxotungstate, $\mathrm{Cu}(\mathrm{II})$ EDTA complex and sodium linker: Synthesis, crystal structures, and magnetic properties. J. Solid State Chem. 2007, 180, 1664-1671. [CrossRef] 
3. Domínguez-Martín, A.; Choquesillo-Lazarte, D.; Dobado, J.A.; Vidal, I.; González-Pérez, J.M.; Castiñeiras, A.; Niclós-Gutiérrez, J. From 7-azaindole to adenine: Molecular recognition aspects on mixed-ligand $\mathrm{Cu}(\mathrm{II})$ complexes with deaza-adenine ligands. Dalton Trans. 2013, 42, 6119-6130. [CrossRef] [PubMed]

4. Domínguez-Martín, A.; Choquesillo-Lazarte, D.; Dobado, J.A.; Martínez-García, H.; Lezama, L.; González-Pérez, J.M.; Castiñeiras, A.; Niclós-Gutiérrez, J. Structural consequences of the N7 and C8 translocation on the metal binding behavior of adenine. Inorg. Chem. 2013, 52, 1916-1925. [CrossRef] [PubMed]

5. Domínguez Martín, A.; Brandi-Blanco, M.P.; Matilla-Hernández, A.; El Bakkali, H.; Nurchi, V.M.; González-Pérez, J.M.; Castiñeiras, A.; Niclós-Gutiérrez, J. Unravelling the versatile metal binding modes of adenine: Looking at the molecular recognition patterns of deaza- and aza-adenines in mixed-ligand metal complexes. Coord. Chem. Rev. 2013, 257, 2814-2818. [CrossRef]

6. Domínguez-Martín, A.; García-Raso, A.; Cabot, C.; Choquesillo-Lazarte, D.; Pérez-Toro, I.; Matilla-Hernández, A.; Castiñeiras, A.; Niclós-Gutiérrez, J. Structural insights on the molecular recognition patterns between N6-substituted adenines and N-(aryl-methyl)iminodiacetate copper(II) chelates. J. Inorg. Biochem. 2013, 127, 141-149. [CrossRef]

7. El Bakkali, H.; Castiñeiras, A.; García-Santos, I.; González-Pérez, J.M.; Niclós-Gutiérrez, J. Metallo-supramolecular structures by self-assembly through weak interactions in mixed ligand metal complexes of adenine and malonate. Cryst. Growth Des. 2014, 14, 249-260. [CrossRef]

8. Pérez-Toro, I.; Domínguez-Martín, A.; Choquesillo-Lazarte, D.; Vílchez-Rodríguez, E.; González-Pérez, J.M.; Castiñeiras, A.; Niclós-Gutiérrez, J. Lights and shadows in the challenge of binding acyclovir, a synthetic purine-like nucleoside with antiviral activity, at an apical-distal coordination site in copper(II)-polyamine chelates. J. Inorg. Biochem. 2015, 148, 84-92. [CrossRef]

9. González-Pérez, J.M.; Choquesillo-Lazarte, D.; Domínguez-Martín, A.; El Bakkali, H.; García-Rubiño, M.E.; Pérez-Toro, I.; Vílchez-Rodríguez, E.; Castiñeiras, A.; Nurchi, V.M.; Niclós-Gutiérrez, J. Molecular recognition between adenine or 2,6-diaminopurine and copper(II) chelates with $\mathrm{N}, \mathrm{O}_{2}, \mathrm{~S}$-tripodal tetradentate chelators having thioether or disulfide donor groups. J. Inorg. Biochem. 2015, 151, 75-86. [CrossRef]

10. González-Pérez, J.M.; Choquesillo-Lazarte, D.; Domínguez-Martín, A.; Vílchez-Rodríguez, E.; Pérez-Toro, I.; Castiñeiras, A.; Arriortua, O.K.; García-Rubiño, M.E.; Matilla-Hernández, A.; Niclós-Gutiérrez, J. The metal binding pattern of acyclovir in ternary copper(II) complexes also having an S-thioether or S-disulfide $\mathrm{NO}_{2}$ S-tripodal tetradentate chelator. Inorg. Chim. Acta 2016, 452, 258-267. [CrossRef]

11. Pérez-Toro, I.; Domínguez-Martín, A.; Choquesillo-Lazarte, D.; García-Rubiño, M.E.; González-Pérez, J.M.; Castiñeiras, A.; Bauzá, A.; Frontera, A.; Niclós-Gutiérrez, J. Copper(II) polyamine chelates as efficient receptors for acyclovir: Synthesis, crystal structures and DFT study. Polyhedron 2018, 145, 218-226. [CrossRef]

12. Pérez-Toro, I.; Domínguez-Martín, A.; Choquesillo-Lazarte, D.; González-Pérez, J.M.; Castiñeiras, A.; Niclós-Gutiérrez, J. The highest reported denticity of a synthetic nucleoside in the unprecedented tetradentate mode of acyclovir. Cryst. Growth Des. 2018, 18, 4282-4286. [CrossRef]

13. Ruiz-González, N.; García-Rubiño, M.E.; Domínguez-Martín, A.; Choquesillo-Lazarte, D.; Franconetti, A.; Frontera, A.; Castiñeiras, A.; González-Pérez, J.M.; Niclós-Gutiérrez, J. Molecular and supra-molecular recognition patterns in ternary copper(II) or zinc(II) complexes with selected rigid-planar chelators and a synthetic adenine-nucleoside. J. Inorg. Biochem. 2020, 203, 110920. [CrossRef] [PubMed]

14. Polyakova, I.N.; Poznyak, A.L.; Segienko, V.S.; Stopolyanskaya, L.V. Crystal Structures of Acid Ethylenediaminotetracetares $\left[\mathrm{Cd}\left(\mathrm{H}_{2} \mathrm{Edta}\right)\left(\mathrm{H}_{2} \mathrm{O}\right)\right] \cdot 2 \mathrm{H}_{2} \mathrm{O}$ and $\left[\mathrm{Mn}\left(\mathrm{H}_{2} \mathrm{O}\right)_{4}\right]\left[\mathrm{Mn}(\mathrm{HEdta})\left(\mathrm{H}_{2} \mathrm{O}\right)\right]_{2} \cdot 4 \mathrm{H}_{2} \mathrm{O}$. Crystallogr. Rep. 2001, 41, 40-45. [CrossRef]

15. Fecher, R.; Boswell, K.H.; Wittick, J.J.; Shen, T.Y. Nucleosides VI: The Synthesis and Optical Properties of the 5'-Adenin-9yl)-5'-Deoxy Derivatives of the Thymidine and 2'-Deoxyadenosine. Carbohydr. Res. 1970, 13, 105-111. [CrossRef]

16. Takenaka, A.; Shibata, M.; Sasada, Y. Three Crystalline Forms of 9-(2-Hydroxyethyl)adenine resulting from the Different Stacking of Hydrogen-Bonded Layers. Acta Crystallogr. 1986, C42, 1336-1340. [CrossRef]

17. BRUKER. APEX3 Software; v2018.7-2; Bruker AXS Inc.: Madison, WI, USA, 2018.

18. Sheldrick, G.M. SADABS. In Program for Empirical Absorption Correction of Area Detector Data; University of Goettingen: Goettingen, Germany, 1997.

19. Sheldrick, G.M. A short history of SHELX. Acta Crystallogr. 2008, A64, 112-122. [CrossRef] 
20. Wilson, A.J.C. International Tables of Crystallography; Vol. C; Kluwer Academic Publishers: Dordrecht, The Netherlands, 1995.

21. Spek, A.L. PLATON. A multipurpose Crystallographic tool. Acta Crystallogr. 2009, D65, 148-155.

22. Frisch, M.J.; Trucks, G.W.; Schlegel, H.B.; Scuseria, G.E.; Robb, M.A.; Cheeseman, J.R.; Scalmani, G.; Barone, V.; Petersson, G.A.; Nakatsuji, H.; et al. Gaussian 16, Revision A.01; Gaussian, Inc.: Wallingford, UK, 2016.

23. Bader, R.F.W. A quantum theory of molecular structure and its applications. Chem Rev. 1991, 91, 893-928. [CrossRef]

24. Keith, T.A. AIMAll (Version 13.05.06); TK Gristmill Software: Overland Park, KS, USA, 2013.

25. Bugella-Altamirano, E.; Choquesillo-Lazarte, D.; González-Pérez, J.M.; Sánchez-Moreno, M.J.; Martín-Ramos, R.; Covelo, B.; Carballo, R.; Castiñeiras, A.; Niclós-Gutiérrez, J. Three new modes of adenine-copper(II) coordination: Interligand interactions controlling the selective N3-, N7- and bridging $\mu$-N3,N7-metal-bonding of adenine to different N-substituted iminodiacetato-copper(II) chelates. Inorg. Chim. Acta 2002, 339, 160-170. [CrossRef]

26. Bader, R.F.W. A Bond Path: A Universal Indicator of Bonded Interactions. J. Phys. Chem. A 1998, 102, 7314-7323. [CrossRef]

27. Belmont-Sánchez, J.C.; Ruiz-González, N.; Frontera, A.; Matilla-Hernández, M.; Castiñeiras, A.; Niclós-Gutiérrez, J. Anion-Cation Recognition Pattern, Thermal Stability and DFT-Calculations in the Crystal Structure of $\mathrm{H}_{2}$ dap $\left[\mathrm{Cd}(\mathrm{HEDTA})\left(\mathrm{H}_{2} \mathrm{O}\right)\right]$ Salt $\left(\mathrm{H}_{2}\right.$ dap $=\mathrm{H}_{2}\left(\mathrm{~N}^{3}, \mathrm{~N}^{7}\right)-2$,6-Diaminopurinium Cation). Crystals 2020, 10, 304. [CrossRef]

28. Roselló, Y.; Benito, M.; Bagués, N.; Martínez, N.; Moradell, A.; Mata, I.; Galcerà, J.; Barceló-Oliver, M.; Frontera, A.; Molins, E. 9-Ethyladenine: Mechanochemical Synthesis, Characterization, and DFT Calculations of Novel Cocrystals and Salts. Cryst. Growth Des. 2020. [CrossRef]

29. García-Raso, A.; Terrón, A.; Ortega-Castro, J.; Barceló-Oliver, M.; Lorenzo, J.; Rodríguez-Calado, S.; Franconetti, A.; Frontera, A.; Vázquez-López, E.M.; Fiol, J.J. Iridium (III) coordination of N(6) modified adenine derivatives with aminoacid chains. J. Inog. Biochem. 2020, 205, 111000. [CrossRef]

30. Martínez, D.; Pérez, A.; Cañellas, S.; Silió, I.; Lancho, A.; García-Raso, A.; Fiol, J.J.; Terrón, A.; Barceló-Oliver, M.; Ortega-Castro, J.; et al. Synthesis, reactivity, X-ray characterization and docking studies of $\mathrm{N}^{7} / \mathrm{N}^{9}$-(2-pyrimidyl)-adenine derivatives. J. Inorg. Biochem. 2020, 203, 110879. [CrossRef]

31. Pons, R.; Ibáñez, C.; Buades, A.B.; Franconetti, A.; Garcia-Raso, A.; Juan J Fiol, J.J.; Angel Terrón, A.; Molins, E.; Frontera, A. Synthesis, X-ray characterization and density functional theory studies of $\mathrm{N}^{6}$-benzyl-N ${ }^{6-}$ methyladenine-M(II) complexes ( $\left.\mathrm{M}=\mathrm{Zn}, \mathrm{Cd}\right)$ : The prominent role of $\pi-\pi, \mathrm{C}-\mathrm{H} \cdots \pi$ and anion- $\pi$ interactions. Appl. Organomet. Chem. 2019, 33, e4906. [CrossRef] 